\title{
Research Paper: Beneficial Effects of Surgical Treat- ment of Compressive Myelopathy in Patients With Severe Angular Kyphosis of Thoracolumbar Spine: A Retrospective Study of 12 Cases
}

\author{
Hasan Ghandhari ${ }^{1}$ (D, Farshad Nikouei ${ }^{1}$, Ebrahim Ameri ${ }^{1}$, Mansour Karimi ${ }^{1}$, Mohammadreza Shakeri ${ }^{{ }^{*}}$ (D)
}

1. Bone and Joint Reconstruction Research Center, Shafa Orthopedic Hospital, Iran University of Medical Sciences, Tehran, Iran

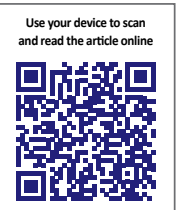

Citation Ghandhari H, Nikouei F, Ameri E, Karimi M, Shakeri M. Beneficial Effects of Surgical Treatment of Compressive Myelopathy in Patients With Severe Angular Kyphosis of Thoracolumbar Spine: A Retrospective Study of 12 Cases. Journal of Research in Orthopedic Science. 2020; 7(3):97-104. http://dx.doi.org/10.32598/JROSJ.7.3.595.1

dof : http://dx.doi.org/10.32598/JROSJ.7.3.595.1

\section{(i) (3)}

Article info:

Received: 10 May 2020

Revised: 22 May 2020

Accepted: 02 Jul 2020

Available Online: 01 Aug 2020

Keywords:

Compressive myelopathy, Kyphosis, Neurological symptoms

\section{A B S T RA C T}

Background: Severe angular kyphosis is one of the uncommon etiologies of compressive myelopathy and hence, many aspects of this myelopathy are unknown.

Objectives: In this study, we report a series of 12 patients with compressive myelopathy in severe angular kyphosis, as well as the result of surgical treatment in these patients.

Methods: In a retrospective study, we included 12 patients with the progressive or sudden onset of paraplegia caused by severe angular kyphosis. The neurological status of the patients was evaluated with the American Spinal Injury Association (ASIA) typing system before the operation and at four time points after the operation (1 day, 1 week, 6 months, 1 year). The main surgical interventions included anterior corpectomy, anterior spinal fusion, and posterior spinal fusion with or without instrumentation and with or without decompression.

Results: The Mean \pm SD age of the patients was $41.9 \pm 16.4$ years, ranging from 14 to 59 years. The etiology of myelopathy was congenital kyphosis in 10 patients $(83.3 \%)$. The Mean \pm SD duration of paralysis was $6.4 \pm 6.6$ months. The Mean \pm SD percentage of cord thinning at the apex was $61.7 \pm 17.5 \%$. Bowel or bladder dysfunction was present in 6 patients $(50 \%)$ before the surgery that was resolved in 5 patients after the surgery. One year after the surgery, the ASIA typing was improved in 9 patients (75\%) and remained the same as preoperative status in 3 patients $(25 \%)$.

Conclusion: Surgical decompression corrects the neurological symptoms in the majority of cases with compressive myelopathy caused by severe angular kyphosis.

\footnotetext{
* Corresponding Author:

Mohammadreza Shakeri, $M D$.

Address: Bone and Joint Reconstruction Research Center, Shafa Orthopedic Hospital, Iran University of Medical Sciences, Tehran, Iran.

Phone: +98 (21) 33542000

E-mail: mshakeri3116@gmail.com
} 


\section{Introduction}

pinal cord compression is associated with S considerable morbidity and mortality [1]. A variety of etiologies in spinal cord compression are known. Severe angular kyphosis is one of the uncommon etiologies of spinal cord compression that is usually caused by congenital kyphosis. Yet, other etiologies such as post-tuberculous kyphosis and posttraumatic kyphosis are also acknowledged. Severe angular kyphosis may lead to compressive myelopathy, a rare and disastrous pathology with challenging surgical treatment, particularly for those with neurologic deficits. The surgical intervention might impose mechanical stress to an already "sick spinal cord," resulting in further neurologic damages and more complicated treatments [2-4].

Despite the difficult management of compressive myelopathy in severe angular kyphosis, many aspects of this disorder are obscure, including its incidence, prognosis, and potential adverse neurologic outcomes of the different surgical approaches $[2,5]$. This is mainly due to the rare occurrence of such disorder and the limited number of papers concerning the compressive myelopathy in severe angular kyphosis. In earlier literature, the outcome of surgical treatment of compressive myelopathy in severe angular kyphosis has only been reported in a small number of case series and it is unclear to what extent the patients will benefit from the surgical intervention. Moreover, in a subset of patients, the neurological status has reported being deteriorated after the operation [2].

In this retrospective study, we report a series of 12 patients with compressive myelopathy caused by severe angular kyphosis, as well as the results of surgical decompression and kyphosis correction.

\section{Methods}

This retrospective study was approved by the Review Board of our institute and the written informed consent was obtained from all patients to use their data for publication. We included patients with compressive myelopathy caused by severe angular kyphosis between 2011 to 2017. The inclusion criteria were the progressive or the sudden onset of paraplegia. Computed Tomography (CT) scanning was used to precisely identify the abnormality and fusion. Magnetic Resonance Imaging (MRI) was used to identify cord compression and the extent of signal intensity alteration. Anteroposterior and lateral radiographs were obtained to assess the balance of the spine in different planes.
Neurological status of the patients was evaluated with the international standards for neurological and functional classification of spinal cord injury published by the American Spinal Injury Association (ASIA) [6], designed in five grades of A. (complete: no sensory or motor function is preserved); B. (sensory incomplete); C. (motor incomplete with a muscle grade less than 3); D. (motor incomplete with a muscle grade more than 3 ); and E. (normal). Neurological status was recorded once before the surgery and at four stages after the surgery (after 1 day, after 1 week, after 6 months, after 1 year).

Main surgical interventions included Anterior Spinal Fusion (ASF) with or without instrumentation and with or without decompression, Posterior Spinal Fusion (PSF) with or without instrumentation and with or without decompression, and anterior corpectomy. All operations were done by one senior spinal surgeon. Intraoperative wake-up test, motor evoked potentials, and somatosensory evoked potential monitoring was not used for any patients. The demographic and clinical characteristics of the patients were extracted from the patients' medical files.

\section{Results}

A total of 12 cases of compressive myelopathy caused by severe angular kyphosis were identified during the study period. The study population comprised 4 males $(33.3 \%)$ and 8 females $(66.7 \%)$ with the Mean \pm SD age of $41.9 \pm 16.4$ years, ranging from 14 to 59 years. The etiology of myelopathy was congenital kyphosis in 10 patients $(83.3 \%)$. The level of paralysis ranged from $\mathrm{T} 10$ to $\mathrm{L} 2$ vertebra. The Mean \pm SD duration of paralysis was 6.4 \pm 6.6 months, ranging from 1 to 24 months. The Babinski sign was upward in 7 patients $(58.3 \%)$ and downward in 5 patients $(41.7 \%)$. The Mean \pm SD percentage of cord thinning at the apex was $61.7 \pm 17.5 \%$ ranging from $40 \%$ to $90 \%$. The clinical and demographic characteristics of the patients are presented in detail in Table 1.

One-stage surgery was performed in 5 patients $(41.7 \%)$, while the surgery was performed in two stages in the other 7 patients (58.3\%) (Figure 1-3). The detailed surgical intervention and outcome are provided in Table 2. The Mean $\pm \mathrm{SD}$ preoperative kyphosis angle was $92.1 \pm 28$ degrees that reduced to $50.2 \pm 38.5$ degrees after the surgery. The Mean \pm SD preoperative scoliosis angle was $23.5 \pm 24$. 1 degrees that reduced to $9.4 \pm 11.4$ degrees after the surgery. Before the operation, 6 patients $(50 \%)$ had bowel or bladder dysfunction which was resolved in 5 of these patients after the operation. One year after the operation, the ASIA typing was improved in 9 patients $(75 \%)$ and remained the same as preoperative status in 
Table 1. The demographic and clinical characteristics of the patients with severe angular kyphosis and compressive myelopathy.

\begin{tabular}{|c|c|c|c|c|c|c|c|c|}
\hline ID & Age (y) & Sex & Etiology & $\begin{array}{l}\text { Level of } \\
\text { Paralysis }\end{array}$ & $\begin{array}{l}\text { Apex of } \\
\text { Kyphosis }\end{array}$ & $\begin{array}{l}\text { Paralysis Duration } \\
\text { (mo) }\end{array}$ & Babinski Sign & $\begin{array}{c}\text { Cord Thinning at } \\
\text { the Apex (\%) }\end{array}$ \\
\hline 1 & 54 & Male & Congenital kyphosis & $\mathrm{T} 10$ & T10-T11 & 5 & Upward & 90 \\
\hline 2 & 14 & Female & Congenital kyphosis & L1 & L1-L2 & 1 & Upward & 90 \\
\hline 3 & 55 & Female & Congenital kyphosis & L2 & L1 & 3 & Upward & 60 \\
\hline 4 & 57 & Female & Chronic osteomyelitis & T12 & $\mathrm{T} 12$ & 1.5 & Downward & 80 \\
\hline 5 & 55 & Male & Congenital kyphosis & T11 & T11-T12 & 8 & Upward & 70 \\
\hline 6 & 29 & Female & Congenital kyphosis & L2 & L2 & 3 & Downward & 60 \\
\hline 7 & 59 & Female & Old nonunion $L 2$ fracture & L2 & L2 & 12 & Upward & 40 \\
\hline 8 & 24 & Female & Achondroplasia & L1 & L1 & 24 & Upward & 50 \\
\hline 9 & 29 & Female & Congenital kyphosis & $\mathrm{T} 12$ & T12-L1 & 10 & Downward & 60 \\
\hline 10 & 50 & Male & Congenital kyphosis & L2 & L2 & 2 & Downward & 50 \\
\hline 11 & 53 & Female & Congenital kyphosis & T10-T11 & $\mathrm{T} 12$ & 1 & Upward & 40 \\
\hline 12 & 24 & Male & Congenital kyphosis & $\mathrm{T} 12$ & $\mathrm{~T} 11$ & 6 & Downward & 50 \\
\hline
\end{tabular}

Table 2. Type of the surgery and surgical outcome in patients with compressive myelopathy caused by severe angular kyphosis

\begin{tabular}{|c|c|c|c|c|c|c|c|}
\hline ID & Type of Surgery & $\begin{array}{c}\text { Pre/Post } \\
\text { Cobb's Angle } \\
\text { (Kyphosis) }\end{array}$ & $\begin{array}{l}\text { Pre/Post Cobb's } \\
\text { Angle (Scoliosis) }\end{array}$ & $\begin{array}{l}\text { Operation Time } \\
\text { (h) }\end{array}$ & $\begin{array}{l}\text { Total Blood } \\
\text { Loss (mL) }\end{array}$ & $\begin{array}{c}\text { ASIA } \\
\text { (pre/1d/1w/6m/1y) }\end{array}$ & $\begin{array}{c}\text { Bowel or Bladder } \\
\text { Dysfunction (Pre/ } \\
\text { Post) }\end{array}$ \\
\hline 1 & *(1) ASF, (2) PSFI & $134^{\circ} / 130^{\circ}$ & $20^{\circ} / 17^{\circ}$ & (1) $3,(2) 2.5$ & $\begin{array}{l}(1) 200,(2) \\
300\end{array}$ & $D / D / D / E / E$ & $+/-$ \\
\hline 2 & $\begin{array}{l}\text { Ant. corpectomy + } \\
\text { decompression \& fusion } \\
\text { (allograft), (2) PSFI }\end{array}$ & $140^{\circ} / 50^{\circ}$ & $14^{\circ} / 10^{\circ}$ & (1) $4,(2) 3$ & $\begin{array}{l}(1) 600,(2) \\
400\end{array}$ & $\mathrm{~A} / \mathrm{C} / \mathrm{D} / \mathrm{D} / \mathrm{D}$ & $+/+$ \\
\hline 3 & $\begin{array}{c}\mathrm{ASFI}+\text { decompression }+ \\
\text { allograft }\end{array}$ & $102^{\circ} / 68^{\circ}$ & $10^{\circ} / 10^{\circ}$ & 5 & 800 & $D / D / D / D / D$ & $+/+$ \\
\hline 4 & $\begin{array}{l}\text { Ant. corpectomy + decom- } \\
\text { pression+ } \\
\text { allograft + instrumentation }\end{array}$ & $65^{\circ} / 10^{\circ}$ & $0^{\circ} / 0^{\circ}$ & $4.5 \mathrm{~h}$ & 600 & $\mathrm{D} / \mathrm{D} / \mathrm{D} / \mathrm{D} / \mathrm{D}$ & $-/-$ \\
\hline 5 & $\begin{array}{c}\text { Ant. corpectomy + } \\
\text { decompression + } \\
\text { allograft + instrumenta- } \\
\text { tion }\end{array}$ & $112^{\circ} / 71^{\circ}$ & $32^{\circ} / 11^{\circ}$ & 5 & 850 & $C / D / D / D / D$ & $-/-$ \\
\hline 6 & $\begin{array}{c}\text { (1) ASF + decompression + } \\
\text { allograft, } \\
\text { (2)PSFI }\end{array}$ & $75^{\circ} / 23^{\circ}$ & $80^{\circ} / 35^{\circ}$ & $\begin{array}{c}2.5 \\
4\end{array}$ & 1450 & $D / D / D / E / E$ & $-/-$ \\
\hline 7 & $\begin{array}{c}\text { Ant. corpectomy + } \\
\text { decompression+ } \\
\text { Allograft + Instrumenta- } \\
\text { tion + PSFI }\end{array}$ & $54^{\circ} /-10^{\circ}$ & $13^{\circ} / 0^{\circ}$ & 6 & 1000 & $C / C / C / D / D$ & $+/+$ \\
\hline 8 & $\begin{array}{c}\text { (1) ASF, (2) PSFI + decom- } \\
\text { pression }\end{array}$ & $84^{\circ} / 36^{\circ}$ & $0^{\circ} / 0^{\circ}$ & 9.5 & $\begin{array}{l}(1) 200,(2) \\
1000\end{array}$ & $C / C / D / D / D$ & $+/-$ \\
\hline 9 & $\begin{array}{c}\text { ASF + corpectomy + de- } \\
\text { compression + allograft, } \\
\text { (2) PSFI }\end{array}$ & $110^{\circ} / 75^{\circ}$ & $55^{\circ} / 25^{\circ}$ & (1) $4,(2) 5$ & $\begin{array}{l}(1) 200,(2) \\
350\end{array}$ & $D / D / D / D / D$ & $-/-$ \\
\hline 10 & $\begin{array}{c}\text { Ant. corpectomy + } \\
\text { decompression +cage + } \\
\text { instrumentation, (2) PSFI }\end{array}$ & $62^{\circ} / 30^{\circ}$ & $0^{\circ} / 0^{\circ}$ & (1) $6,(2) 5$ & $\begin{array}{l}\text { (1) } 4300,(2) \\
1750\end{array}$ & $D / D / D / E / E$ & $-/-$ \\
\hline 11 & PSFI + decompression & $94^{\circ} / 90^{\circ}$ & $28^{\circ} / 5^{\circ}$ & 4 & 800 & $C / C / C / D / D$ & $+/-$ \\
\hline 12 & $\begin{array}{l}\text { Ant. corpectomy + de- } \\
\text { compression + allograft, } \\
\text { (2) PSFI + PSO }\end{array}$ & $74^{\circ} / 30^{\circ}$ & $30^{\circ} / 0^{\circ}$ & (1) 4, , (2) 5 & $\begin{array}{l}\text { (1)700, } \\
\text { (2)1800 }\end{array}$ & $D / D / D / E / E$ & $-/-$ \\
\hline
\end{tabular}

Orthopedic Scienc

*In case the number is not provided, all the surgeries have been done simultaneously. Otherwise, two-step surgeries have been implemented. Abbreviations: Ant, anterior; PSF, posterior spinal fusion; PSFI, posterior spinal fusion with instrumentation; ASF, anterior spinal fusion; ASFI, anterior spinal fusion with instrumentation; PSO, pedicle subtraction osteotomy. 

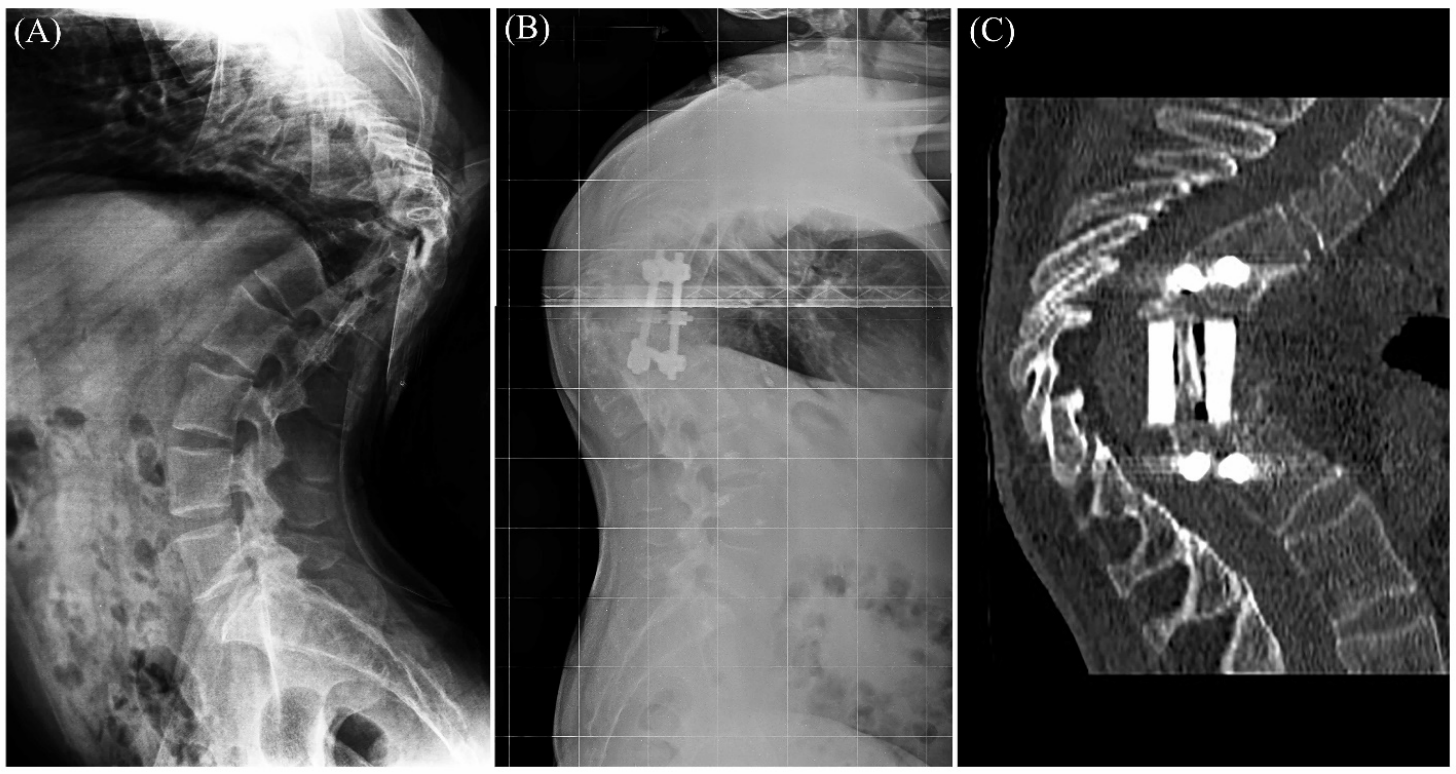

Orthopedic Science

Figure 1. A. Lateral radiograph of a 55-year-old male showing compressive myelopathy caused by congenital kyphosis (case 5); B. Lateral radiograph of the same patients showing the kyphosis correction with anterior corpectomy, decompression, strut allograft reconstruction, and instrumentation; C. Postoperative sagittal CT scan of the same patient confirming the radiographic findings

3 patients $(25 \%)$. No ASIA typing deterioration was observed in our series (Table 2).

\section{Discussion}

Considering the rare incidence of severe angular kyphosis, the beneficial effects of surgical treatment of compressive myelopathy in these patients is not well-un- derstood. It is unclear to what extent the patients would benefit from surgical intervention. In a subset of patients, the neurologic status might even deteriorate after the surgery, which further complicates the current uncertainties. In this situation, reports of the outcome of surgical treatment in these patients could be regarded as a valuable approach to resolve the existing concerns.
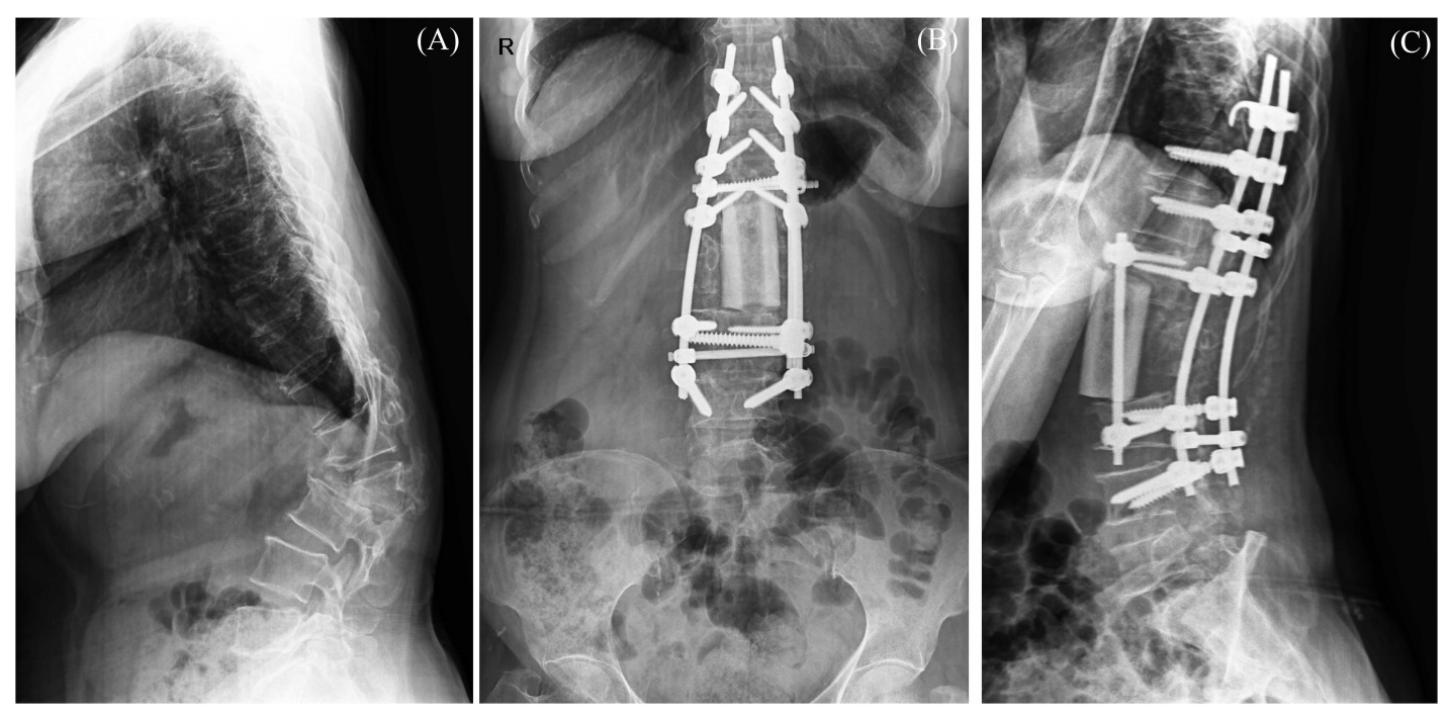

Orthopedic Science

Figure 2. A. Lateral radiograph of a 59-year-old female revealing compressive myelopathy caused by L2 nonunion (case 7); B. Anteroposterior radiograph of the same patient after one-step surgery including anterior corpectomy, decompression, strut allograft reconstruction, and posterior spinal fusion with instrumentation; C. Lateral radiograph of the same patient after the surgery showing kyphosis correction 

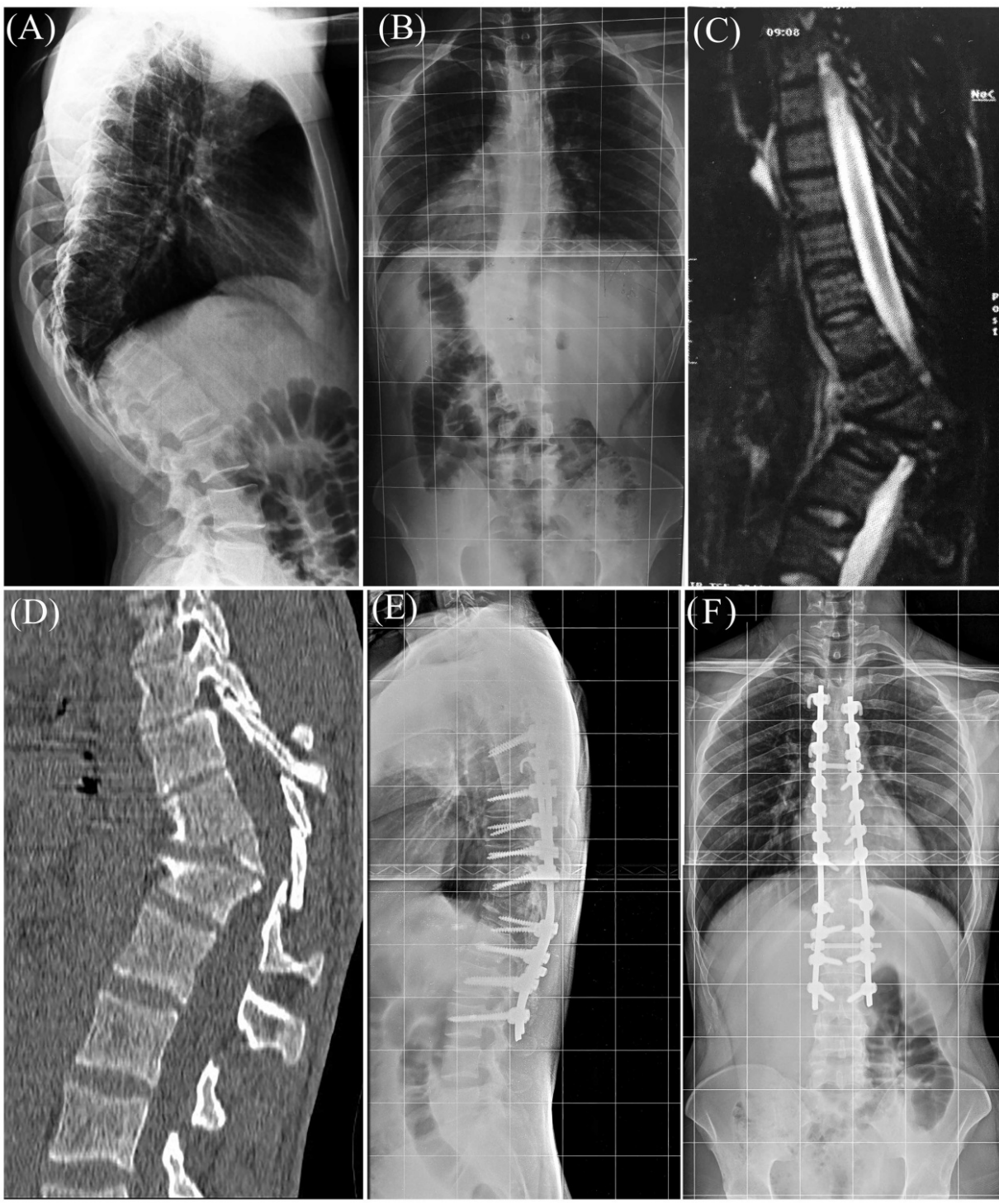

Orthopedic Science

Figure 3. A. Lateral; and B. Anteroposterior radiographs of a 24-year-old male showing compressive myelopathy caused by congenital kyphosis (case 12); C. Sagittal T2-weighted MRI of the same patient showing spinal cord compression and thinning at the apical curve; D. Sagittal CT scan of the same patient before the surgery confirming the MRI findings; E. Lateral radiograph of the same patient after two-step surgery performed by anterior corpectomy, decompression, strut allograft reconstruction, and posterior spinal fusion with instrumentation; F. Anteroposterior radiograph of the same patient after the surgery showing kyphosis correction

According to the study results, congenital kyphosis was the most frequent etiology of compressive myelopathy in severe angular kyphosis. Surgical intervention results in the improvement of neurological symptoms in the majority of patients, including their bowel/bladder dysfunction. In this respect, bowel or bladder dysfunction resolved in $5(83.3 \%)$ out of 6 patients after the surgery. Besides, the neurological status improved in $9(75 \%)$ out of 12 patients and remained the same as preoperative status in 3 patients $(25 \%)$. No neurological symptoms deterioration was observed in patients of the current series.
To date, compressive myelopathy in severe angular kyphosis has only been reported in a small number of case series.

In the study of Zhang et al., 10 patients with severe angular kyphosis and a progressive or a sudden onset of paraplegia were surgically treated [2]. Song et al. [3] and Chang et al. [4] also reported a series of 17 and 16 patients with compressive myelopathy in angular kyphosis of the thoracic spine, respectively. While the dominant etiology was congenital kyphosis in Zhang's study (8 out 
of 10 cases) as well as ours (10 out of 12 cases). Pott's kyphosis was the most common diagnosis in the study of Song et al. as well as Chang et al. (7 out of 16 cases and 11 out of 17 cases, respectively). The most common apex of the kyphosis was the lower thoracic spine in the study of Song et al. (10 out of 16 cases) as well as Change el. (14 out of 17 cases). Yet, the most common apex of kyphosis was upper thoracic spine (6 out of 10 cases) in the study of Zhang et al. The apex of kyphosis was equally distributed between lower thoracic spine and upper lumbar spine in our series.

$\mathrm{KY}$ and $\mathrm{YH}$ reported the outcome of the treatment of neurological deficit in 36 patients with severe angular kyphosis caused by spondylitis secondary to tuberculosis. An improvement of the neurological symptoms, evaluated by the ASIA impairment scale, occurred in 4 out of 9 patients $(44.4 \%)$ who were treated surgically [7].

The mean age of patients in the current series was 41.9 years. The onset of the neurological deficit was more than 16 years of age in 9 out of 10 cases of congenital kyphosis that was not in accordance with the earlier investigations $[2,8,9]$.

The reduction of spinal cord diameter at the apex was $40 \%-80 \%$ in the study of Zhang et al. This level of cord thinning in patients with congenital kyphosis presented with paraplegia was in accordance with the earlier investigations [10-12]. The percentage of spinal cord thinning ranged from $40 \%$ to $90 \%$ in our patients at the time of presentation.

Correction of spinal deformity has been reported as a risk factor of spinal cord injury in many investigations [13-15]. In this respect, the ASIA typing deteriorated in one of the cases of the study of Zhang et al. Yet, no ASIA type deterioration was recorded in our series. Several factors might affect the outcome of spinal correction surgery, including the intraoperative spinal cord vessels or neural tissue distortion, spinal cord impingement at the edges of decompression, blood loss, etc. [13]. The ASIA typing improved in all patients of the studies of Song et al. and Chang et al. but not in some patients with ASIA type A. The ASIA typing improved in 9 cases of our series. The initial ASIA type was D in these patients and remained the same in the last follow-up.

Atici et al. analyzed the complications of Posterior Vertebral Column Resection (PVCR) for the treatment of 17 patients with severe angular kyphosis $>100^{\circ}$. Complications occurred in 12 patients $(70.6 \%)$, comprising spinal shock $(n=4)$, hemothorax $(n=3)$, postoperative infection $(n=2)$, dural laceration $(n=2)$, neurological deficit $(n=2)$, the shifted cage $(n=2)$, and rod fracture $(n=2)$. Neurological events occurred in 6 patients $(35 \%)$ which were temporary in 5 patients and permanent in the other one. They concluded that although PVCR is an efficient technique for the correction of severe angular kyphosis, it is associated with several major complications [16].

Zhang et al. suggested factors such as the patient's age (over 20 years old), the kyphosis angulation (over 120 degrees), and gradual onset of paraplegia as the indicators of poor prognosis in congenital kyphosis after surgery. Particularly, the preoperative duration of paraplegia and the severity of paraplegia before the surgery were mentioned as the key factors for adverse postoperative neurological prognosis [2]. Yet, these factors did not seem to be determinative of the outcome in our series. However, to prevent further neurological defects, it is safer to perform decompression surgery when spinal cord compression and cord thinning at the apex are seen in MRI and adequate decompression can be achieved surgically.

This study was not without limitations. The retrospective design and a small number of patients could be regarded as the main limitations of this study. However, it should be noted that available case series are the best way to gather information regarding the outcome of surgical treatment of compressive myelopathy in patients with severe angular kyphosis.

Altogether, our study reveals that severe angular congenital kyphosis could result in compressive myelopathy with serious neurological impairments. As the surgical decompression is shown to correct the neurological symptoms in the majority of cases, it is suggested to perform surgical intervention as soon as the spinal cord compression is detected. Delay in surgery might lead to a more complicated operation and impose a further risk of neurological damages to an already vulnerable patient. Yet, it should be noticed that complete recovery might not be achievable and this should be discussed with the patients and their families.

\section{Ethical Considerations}

\section{Compliance with ethical guidelines}

All ethical principles are considered in this article. The participants were informed about the purpose of the research and its implementation stages; they were also assured about the confidentiality of their information; moreover, they were free to leave the study whenever they wished, and if desired, the research results would be available to them. 


\section{Funding}

This research did not receive any grant from funding agencies in the public, commercial, or non-profit sectors.

\section{Authors' contributions}

All authors contributed in preparing this article.

\section{Conflict of interest}

The authors declared no conflict of interest.

\section{References}

[1] Schiff D. Spinal cord compression. Neurol Clin. 2003; 21(1):67-86. [DOI:10.1016/S0733-8619(02)00033-6]

[2] Zhang Z, Wang H, Liu C. Compressive myelopathy in severe angular kyphosis: A series of ten patients. Eur Spine J. 2016, 25(6):1897-903. [DOI:10.1007/s00586-015-4051-6] [PMID]

[3] Song KS, Chang BS, Yeom JS, Lee JH, Park KW, Lee CK. Surgical treatment of severe angular kyphosis with myelopathy: Anterior and posterior approach with pedicle screw instrumentation. Spine. 2008; 33(11):1229-35. [DOI:10.1097/ BRS.0b013e31817152b3] [PMID]

[4] Chang KW, Cheng CW, Chen HC, Chen TC. Correction hinge in the compromised cord for severe and rigid angular kyphosis with neurologic deficits. Spine. 2009; 34(10):1040-5. [DOI:10.1097/BRS.0b013e31819c105f] [PMID]

[5] Cornips E, Koudijs S, Vles J, van Rhijn L. Childhood angular kyphosis: A plea for involvement of the pediatric neurosurgeon. Childs Nerv Syst. 2017; 33(6):973-81. [DOI:10.1007/ s00381-017-3389-y] [PMID] [PMCID]

[6] Maynard FM, Bracken MB, Creasey G, Ditunno JF, Donovan $\mathrm{WH}$, Ducker TB, et al. International standards for neurologi$\mathrm{cal}$ and functional classification of spinal cord injury. Spinal cord. 1997; 35(5):266-74. [DOI:10.1038/sj.sc.3100432] [PMID]

[7] Ha KY, Kim YH. Late onset of progressive neurological deficits in severe angular kyphosis related to tuberculosis spondylitis. Eur Spine J. 2016; 25(4):1039-46. [DOI:10.1007/ s00586-015-3997-8] [PMID]

[8] Winter R, Moe J, Wang J. Congenital kyphosis: Its natural history and treatment as observed in a study of one hundred and thirty patients. J Bone Joint Surg. 1973; 55(2):223-74. [DOI:10.2106/00004623-197355020-00001] [PMID]

[9] McMaster MJ, Singh H. Natural history of congenital kyphosis and kyphoscoliosis: A study of one hundred and twelve patients. J Bone Joint Surg. 1999; 81(10):1367-83. [DOI:10.2106/00004623-199910000-00002] [PMID]

[10] Jung SH, Bang MS. A case of congenital kyphosis misdiagnosed as cerebral palsy. Childs Nerv Syst. 2007; 23(10):12058. [DOI:10.1007/s00381-007-0377-7] [PMID]
[11] Aguiar CA, Mendoza-Lattes S, Cobb P, Menezes A, Weinstein SL. Unusual association of congenital kyphosis and conus lipoma presenting as a double spinal cord tether. Iowa Orthop J. 2007; 27:85.

[12] Sugimoto Y, Tanaka M, Nakahara R, Misawa H, Kunisada T, Ozaki T. Surgical treatment for congenital kyphosis correction using both spinal navigation and a 3-dimensional model. Acta Med Okayama. 2012; 66(6):499-502.

[13] Kawahara N, Tomita K, Kobayashi T, Abdel-Wanis ME, Murakami $\mathrm{H}$, Akamaru T. Influence of acute shortening on the spinal cord: An experimental study. Spine. 2005; 30(6):613-20. [DOI:10.1097/01.brs.0000155407.87439.a2] [PMID]

[14] Jalanko T, Rintala R, Puisto V, Helenius I. Hemivertebra resection for congenital scoliosis in young children: Comparison of clinical, radiographic, and health-related quality of life outcomes between the anteroposterior and posterolateral approaches. Spine. 2011; 36(1):41-9. [DOI:10.1097/ BRS.0b013e3181ccafd4] [PMID]

[15] Bollini G, Docquier PL, Viehweger E, Launay F, Jouve JL. Thoracolumbar hemivertebrae resection by double approach in a single procedure: Long-term follow-up. Spine. 2006; 31(15):1745-57. [DOI:10.1097/01.brs.0000224176.40457.52] [PMID]

[16] Atici Y, Balioglu MB, Kargin D, Mert M, Albayrak A, Kaygusuz MA. Analysis of complications following posterior vertebral column resection for the treatment of severe angular kyphosis greater than 100. Acta Orthop Traumatol Turc. 2017 51(3):201-8. [DOI:10.1016/j.aott.2017.02.015] [PMID] [PMCID] 
This Page Intentionally Left Blank 